\title{
RAINFALL AND LANDSLIDES IN KARDITSA COUNTY (GREECE): A STATISTICAL APPROACH
}

\author{
Pyrgiotis L. ${ }^{1}$, Koukis G. ${ }^{2}$, and Sabatakakis N. ${ }^{2}$ \\ ${ }^{1}$ I.G.M.E., Department of Engineering Geology, Mesogion Str. 70, 115 27, Athens, Greece, \\ lpyrg@igme.gr \\ ${ }^{2}$ University of Patras, Department of Geology, Section of Applied Geology and Geophysics, Rio \\ Patras,26504,Patras, Greece,g.koukis@upatras.gr,sabatak@upatras.gr
}

\begin{abstract}
The mountainous area of Karditsa County, being geologically a representative sample of Olonos- Pindos geotectonic zone, is characterized by rainfall-induced landslides on steep slopes of high relief. After a systematic data inventory concerning landslides and their quantitative expression, the correlation between landslide occurrence and rainfall is investigated. Following the analyses performed a close interrelation between landslides and precipitation is established. Finally, a characteristic example of rainfall-induced landslide in the wider area of the county is given. Key words: Precipitation, instability, correlation.
\end{abstract}

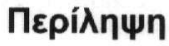

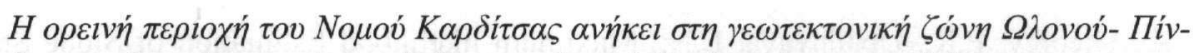

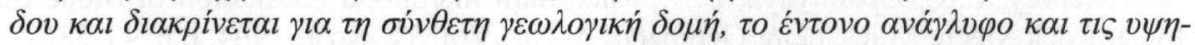

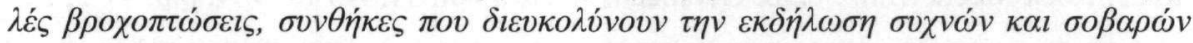

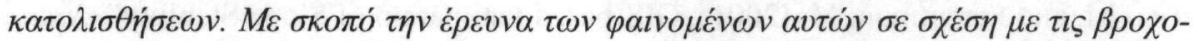

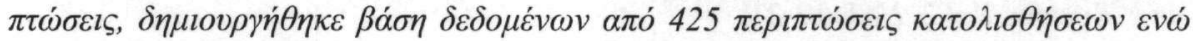

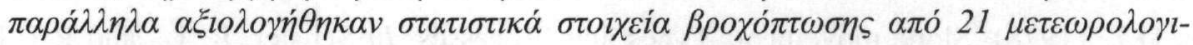

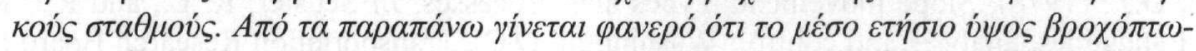

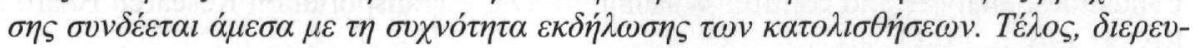

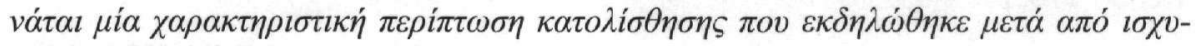
$\rho \varepsilon \dot{\varsigma} \beta \rho о \chi о \pi \tau \omega ́ \sigma \varepsilon ı$.

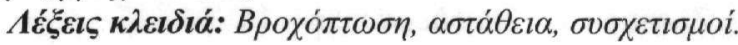

\section{Introduction}

Rainfall constitutes one of the more important exogenic factors that contribute the occurrence of landslides and facilitate the triggering of movement. The participation of rainfall in the problem of landslides is multiple. Thus the water after rapid, high-intensity rainfall erodes and undermines the slopes along rivers and torrents, increases the pore pressure, causes internal erosion or even swelling of clay materials and moreover adds weight to the unstable masses. Still it weakens the slip surface and facilitates weathering (Terzaghi 1950, Varnes 1978, 1984, Koukis- Ziourkas 1991).

For the investigation of the role of rainfall in the landslide occurrence of some area, the continuous observation and recording of rainfall duration, intensity and amount is essential. The presentation 
of these elements in diagrams allows the comparison with equivalents that concern the frequency, development rate, etc. of the landslides and mainly for periods where the above parameters take values considerably higher than average (Zaruba- Mencl 1969, Radbruck-Hall- Crawther 1973, Lumb 1975, Koukis et al. 1996, Nikolaou et al. 1997). Also a relatively dense network of meteorological stations in a region with high frequency of landslides is a component of a landslide warning system (Keefer et al. 1987).

The absence of recorded observations of the actual time and the date of landslide occurrence prevents the application of the above methodology in the Karditsa County. Consequently this study was based exclusively on the mean annual precipitation.

The western mountainous part of Karditsa County is geologically occupied by the Olonos- Pindos Zone formations, which are characterized by varying lithological composition and physicomechanical characteristics, and they have been subjected to strong folding and rupturing. These factors, in combination with the intense relief, the heavy rainfall and man's intervention, facilitate the occurrence of frequent and sometimes extensive landslide movements. In this county, a systematic research on landslides has been carried out by compiling an inventory of critical parameters that affect landslide phenomena, which helped in building a database. This database included a complete recording system that contains all existent data from technical reports, as well as those data obtained by fieldwork. Also the research investigated the factors that contribute to the problem using statistical analysis of the parameters (Pyrgiotis 1997).

The data collected and evaluated, come from more than 400 cases and they cover a long time span (1949- 1995). Most of these landslides affect small parts of the slopes and their occurrence is due to the combined effects of many factors such as lithology and stratigraphy, orientation of bedding, morphology, altitude, rainfall, seismicity etc.

In the following, we compare annual rainfall with frequency of landslide occurrence in Karditsa County. Also, one characteristic example of rainfall-induced landslide in the wider area of the county is described.

\section{Geomorphology-Geological setting}

The county of Karditsa occupies the south-western part of Thessaly prefecture and comprises two physiographic regions, the mountainous region (altitude higher than $200 \mathrm{~m}$ ) which makes up $51,4 \%$ of the total and the lowland $(48,6 \%)$ that constitutes the southwestern part of Thessalian plain (Fig. 1).

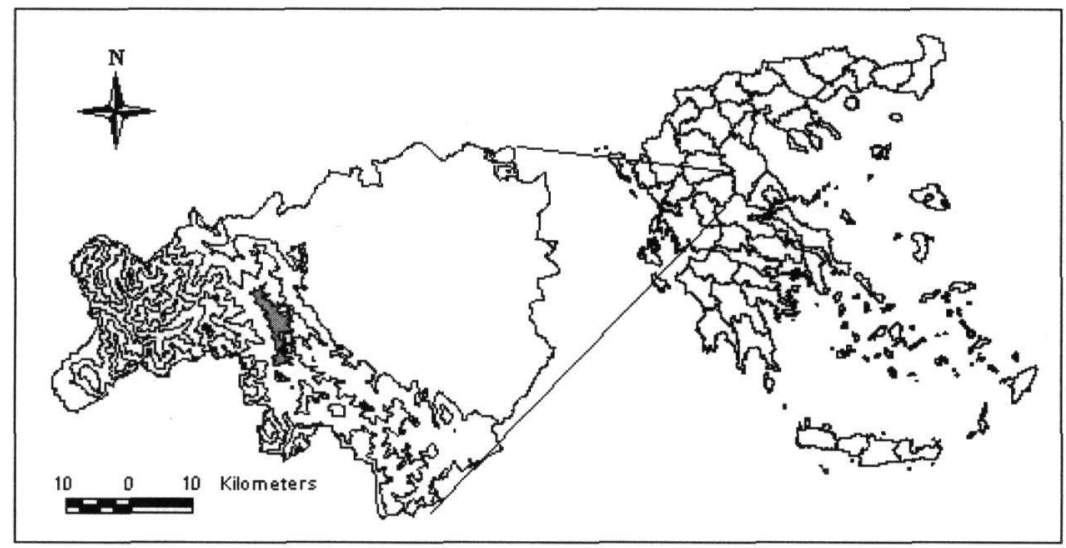

Figure 1 - Geomorphological map of Karditsa county 
The position of the county, from the geological point of view, between the internal and external Hellenides adjoined with the geotectonic evolution in progress of the Thessalian basin, indicates the particularity of the prevailing geological formations. The geotectonic zones built within the county are the following, from E to W: 1) Pelagonian, 2) Sub- Pelagonian, 3) Ultra-Pindic, 4) Olonos-Pindos and 5) Gavrovo-Tripolis.

Besides the formations of these zones a significant part of the county is occupied by the postalpine sediments such as the Molassic formations of the Meso-Hellenic Trough and the Quaternary deposits of the Thessalian plain.

\section{Hydro- meteorological regime}

For the estimate of precipitation amount in the wider area of Karditsa area, the data obtained from 21 meteorological stations, homogeneously distributed in the county and covering a period of more than 32 years (1961-1993), have been evaluated and analyzed. The reliability control and the extension of the above data were performed with statistical methods and based on comparison of elements between neighboring meteorological stations.

Recounting the distribution of the meteorological stations in the county and the mean annual amount of the rainfall for each one, a 1:100,000 scale map of rainfall has been compiled (Fig. 2).

The highest frequency of landslide occurrence in the county, as above recorded, occurs in the mountainous western region of it. Taking into account the total of examined meteorological stations in this part of the county (17 stations from a total of 21$)$ as well as the mean annual precipitation of each one, a pie chart was constructed (Fig. 3). Precipitation was subdivided into nine categories $(<600 \mathrm{~mm}, 600-800 \mathrm{~mm}, 800-1000 \mathrm{~mm}, 1000-1200 \mathrm{~mm}, 1200-1400 \mathrm{~mm}, 1400$ $1600 \mathrm{~mm}, 1600-1800 \mathrm{~mm}, 1800-2000 \mathrm{~mm},>2000 \mathrm{~mm})$. This chart indicates that the mean annual precipitation in the majority of the meteorological stations $(66 \%)$ falls into the categories of 1000 $1200 \mathrm{~mm}$ and $1200-1400 \mathrm{~mm}$.

Also, in Figure 4 the distribution of mean annual rainfall of the above stations for the period 19611993 is given. An increase during the years 1962-1963, 1966, 1979-1980, 1982, 1985 and 1987 is indicated.

\section{Precipitation and Landslides}

In Karditsa County the occurrence of landslides is very frequent and large numbers occurred during several years. As a consequence, serious social, economic and technical problems have arisen, because the landslides affect technical works (transportation network, extensive engineering works etc.) with immediate effects to urban development. These phenomena mainly concern zones of older activation due to geological factors as well as recent ones due to human activity and precipitation peaks.

The need of quantitative expression of data referring to landslide movements in Karditsa County gave incentive to the development of a complete recording system. To this direction, for the detailed investigation of all the parameters (lithological composition and structure, geometry of slope, hydrogeological conditions, causes, movement mechanism, consequences, remedial measures and their results) involved in the problem of landslides, a systematic inventory of data was implemented and a database was developed.

The number of data collected is very large, consisting of 425 cases (in urban mainly areas, natural and artificial slopes) and covers a long time span (1949-1995). The distribution of the landslides within the county is given in the map of Figure 2. 


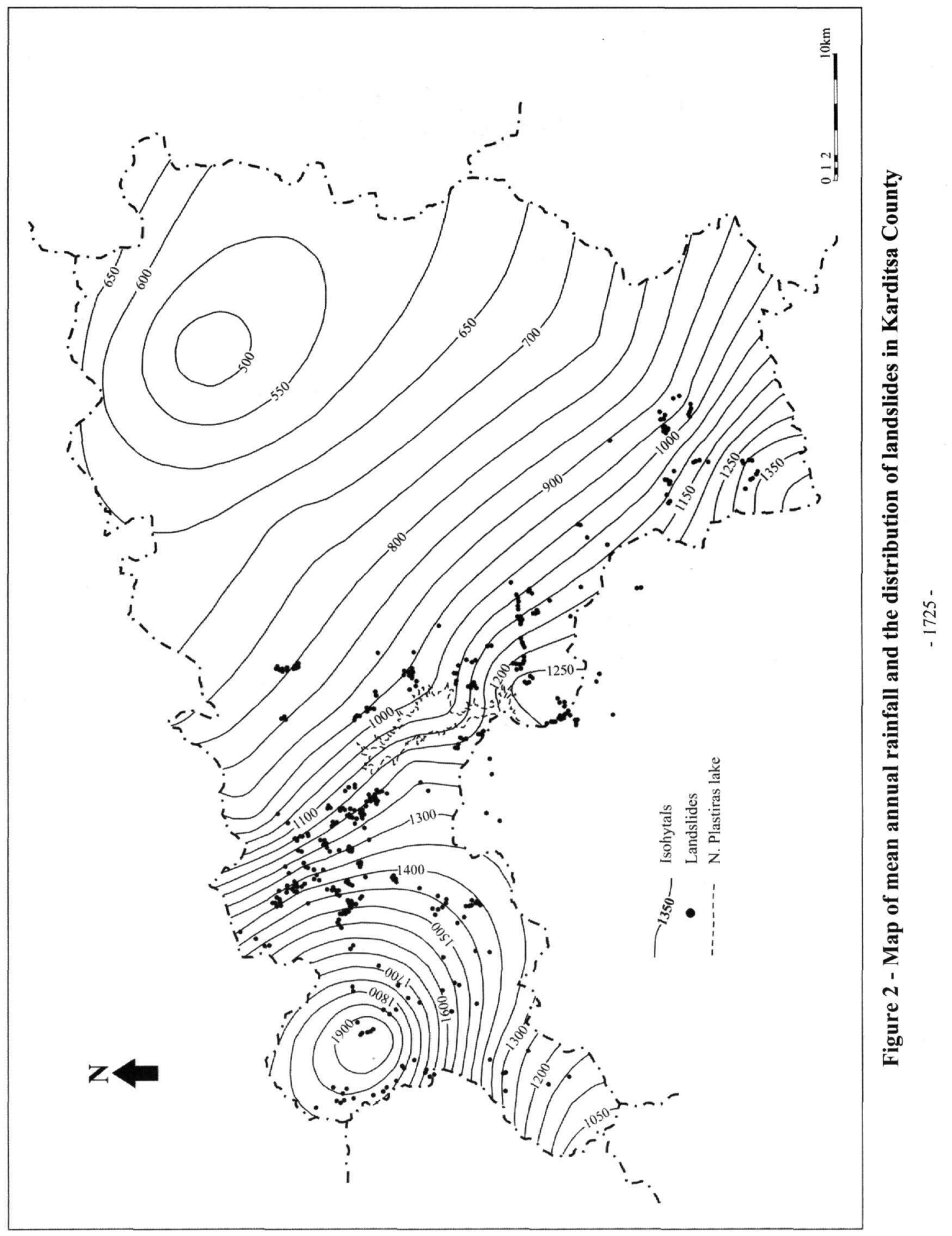




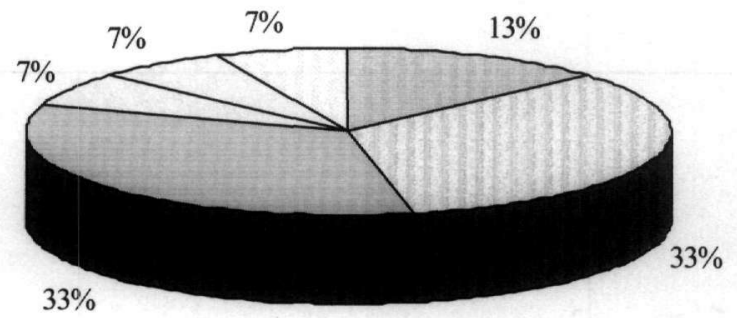
$\square 800-1000 \mathrm{~mm}$
$\square 1000-1200 \mathrm{~mm}$
$\square 1200-1400 \mathrm{~mm}$
$\square 1400-1600 \mathrm{~mm}$
$\square 1600-1800 \mathrm{~mm}$
$\square 1800-2000 \mathrm{~mm}$

Figure 3 - Distribution of the mean annual rainfall in precipitation categories for the meteorological stations on the mountainous region

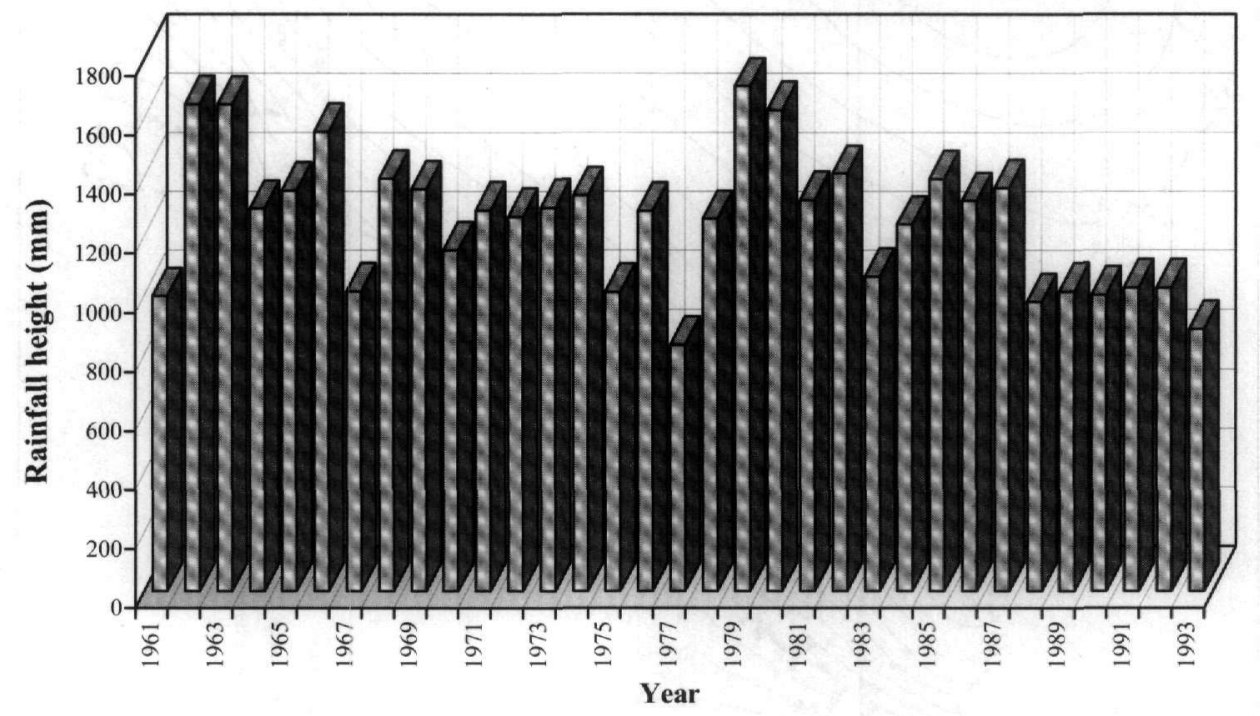

Figure 4 - Distribution of the mean annual rainfall for the mountainous region of the county

Based on the frequency of mean annual amount of rainfall within the landslide affected areas for the total of studied cases it is derived that $97.41 \%$ of these corresponds to mean annual rainfall amount $>800 \mathrm{~mm}$ and particularly in the precipitation categories of $1000-1200 \mathrm{~mm}(31.76 \%)$ and 1200- $1400 \mathrm{~mm}(26.35 \%)$ (Table 1, Fig. 5).

If the geographical extent covering each category of the mean annual rainfall amount in the Karditsa County is taken into account (Table 1), it is evident that the landslide frequency increases greatly (Fig. 6). It should also be noted that most of the landslides are manifested during the period of heavy rainfall, while during the rest of the year a significant decrease is observed both for the first movement and the reactivation of these phenomena.

Focusing in the mountainous region of Karditsa County, a frequency diagram of landslides for the period 1961- 1993 is given (Fig. 7). The largest number of mass movements occurred during the years 1963 (29 cases), 1979 (30 cases), 1982 (16 cases), 1985 (41 cases) and 1987 (18 cases). 
Analysis of landslide locations in relation to mean annual precipitation shows that landslide phenomena which occurred in the above period are mainly concentrated in the precipitation categories 1001- $1200 \mathrm{~mm}$ and 1201- $1400 \mathrm{~mm}$ (Fig. 8).

Table 1 - Frequency distribution of landslides per precipitation category for the total of the studied cases

\begin{tabular}{|l|c|c|c|c|c|}
\hline Rainfall heigh & $\begin{array}{c}\text { No of } \\
\text { landslides }\end{array}$ & $\begin{array}{c}\mathbf{A}_{\mathbf{1}} \text { Frequency of } \\
\text { landslides (\%) }\end{array}$ & $\mathbf{A}_{\mathbf{2}}$ Area (\%) & $\mathbf{A}_{\mathbf{1}} / \mathbf{A}_{\mathbf{2}}$ & $\begin{array}{c}\text { Relative } \\
\text { frequency (\%) }\end{array}$ \\
\hline$<600 \mathrm{~mm}$ & 0 & 0.00 & 16.30 & 0.000 & 0.00 \\
\hline $600-800 \mathrm{~mm}$ & 11 & 2.59 & 30.80 & 0.084 & 0.67 \\
\hline $800-1000 \mathrm{~mm}$ & 54 & 12.71 & 18.30 & 0.694 & 5.56 \\
\hline $1000-1200 \mathrm{~mm}$ & 135 & 31.76 & 12.90 & 2.462 & 19.74 \\
\hline $1200-1400 \mathrm{~mm}$ & 112 & 26.35 & 10.40 & 2.534 & 20.31 \\
\hline $1400-1600 \mathrm{~mm}$ & 71 & 16.71 & 5.60 & 2.983 & 23.91 \\
\hline $1600-1800 \mathrm{~mm}$ & 18 & 4.24 & 2.90 & 1.460 & 11.71 \\
\hline $1800-2000 \mathrm{~mm}$ & 24 & 5.65 & 2.50 & 2.259 & 18.10 \\
\hline$>2000 \mathrm{~mm}$ & 0 & 0.00 & 0.30 & 0.000 & 0.00 \\
\hline \multicolumn{1}{|c|}{ Total } & 425 & 100.00 & 100.00 & 12.477 & 100.00 \\
\hline
\end{tabular}

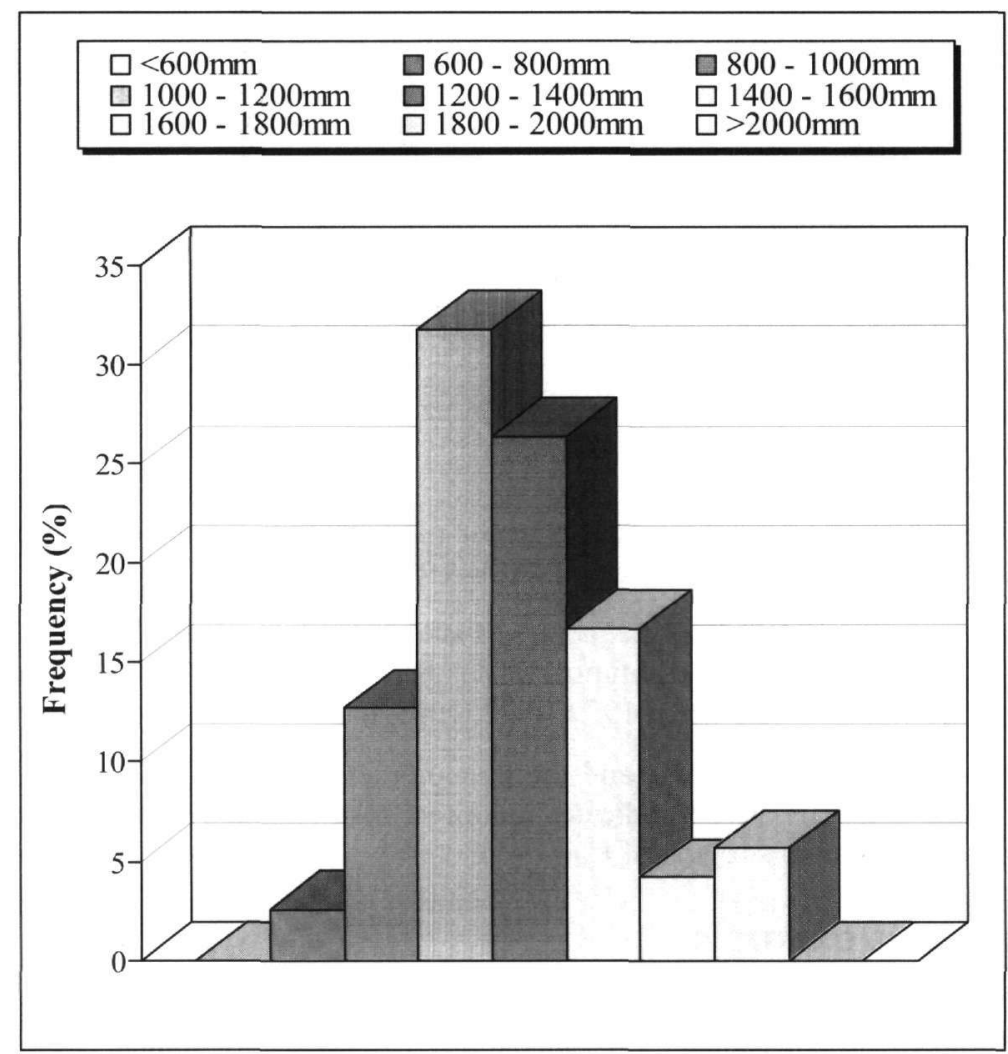

Figure 5 - Frequency distribution histogram of landslides according to mean annual rainfall for the cases studied 


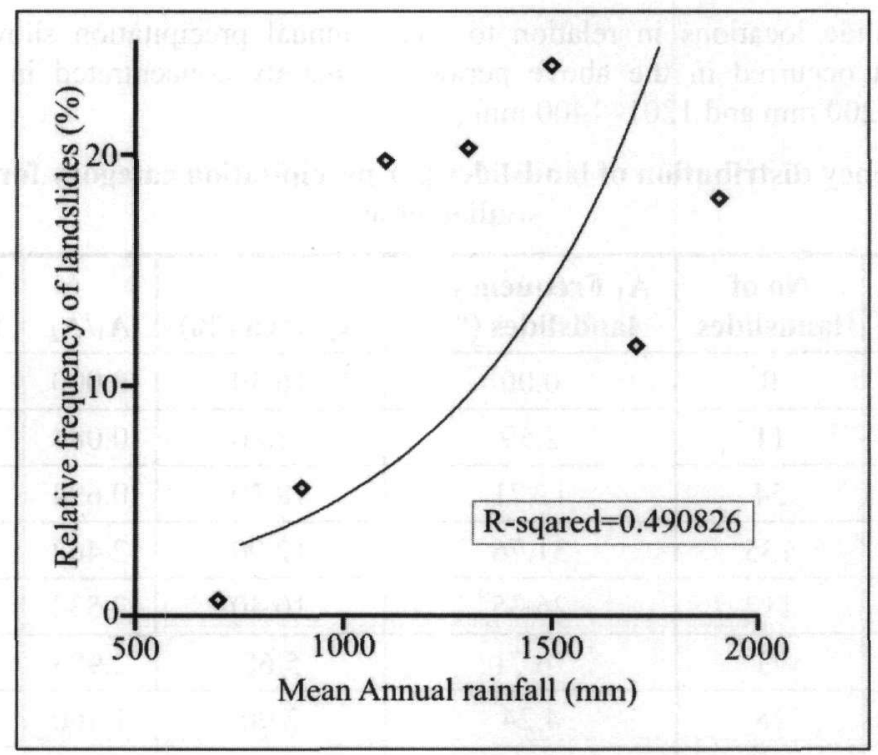

Figure 6 - Correlation between relative frequency of landslides and mean annual rainfall

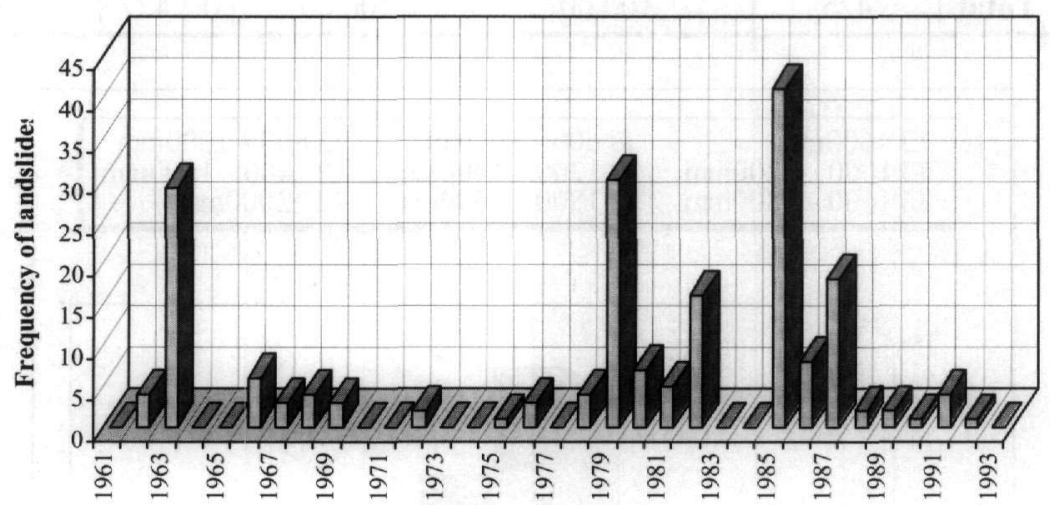

Figure 7 - Frequency of recorded landslides in the mountainous region of the county for the period 1961- 1993

The diagram of Figure 9 combines the frequency of landslides for each precipitation category and year. This clearly shows the increased number of landslides into the 1001- $1200 \mathrm{~mm}$ and 1201$1400 \mathrm{~mm}$ categories and the years 1963,1979, 1982, 1985 and 1987.

Finally, using the number of landslides and the precipitation per year, the combined diagram of Figure 10 was compiled. This clearly indicates the direct relationship of landslide occurrence and precipitation in the mountainous region of Karditsa County.

\section{Characteristic example}

A characteristic example of rainfall- induced landslide in the mountainous region of the county is analyzed. More specifically, in January 1963 an extensive landslide took place in the wider area of Stefaniada, a small village SW of Mouzaki city. The landslide materials blocked the 
Koumpourgianitikos stream with the creation of a natural dam in this place (Fig. 11). Also buildings founded in the area of landslide were completely destroyed while a human life was lost.

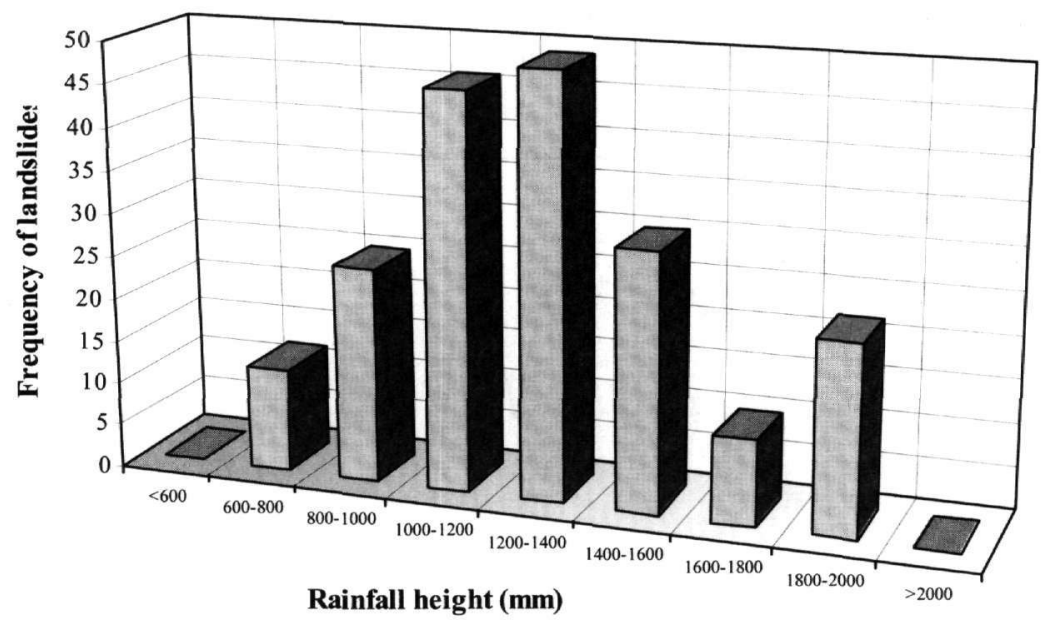

Figure 8 - Distribution of landslides in each precipitation category for the period 1961- 1993

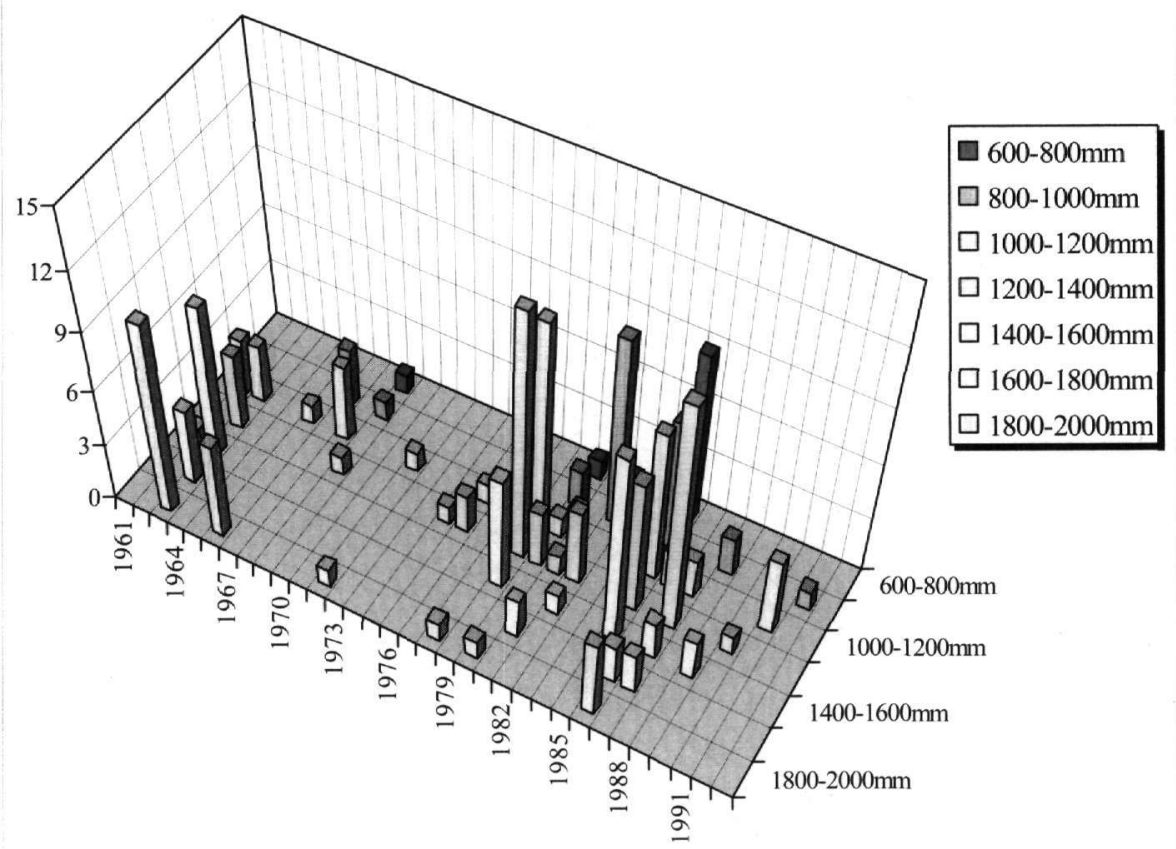

Figure 9 - Frequency distribution of landslides per year and per precipitation category for the period 1961- 1993

Geologically, the area surrounding the landslide is occupied by Mesozoic limestones (JurassicCretaceous) of Olonos- Pindos zone and the presence of first flysch (alternations of thin beds of marls, cherts, marly limestones and shales). This last formation is highly folded and fractured. 
The hydrologic year 1962- 1963 was the wettest one for the last 50 years. This fact contributed to the occurrence of a significant number of landslides in the wider area of the county. So the extended rainfall, the undermining at the base of the slope by Koumpourgianitikos stream as well as the intense tectonic fracturing of flysch formations were the most important factors that contributed in the occurrence of the above phenomenon in Stefaniada area.

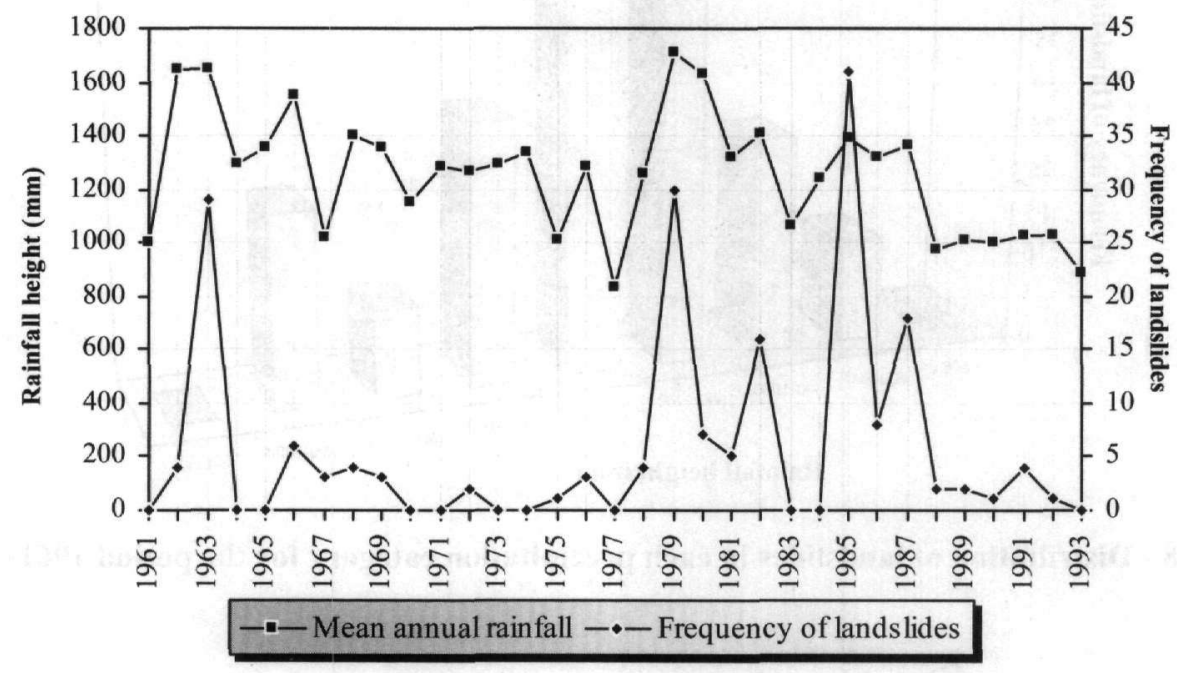

Figure 10 - Combined diagram showing the course of landslides and precipitation in the mountainous region of the county for the period 1961- 1993

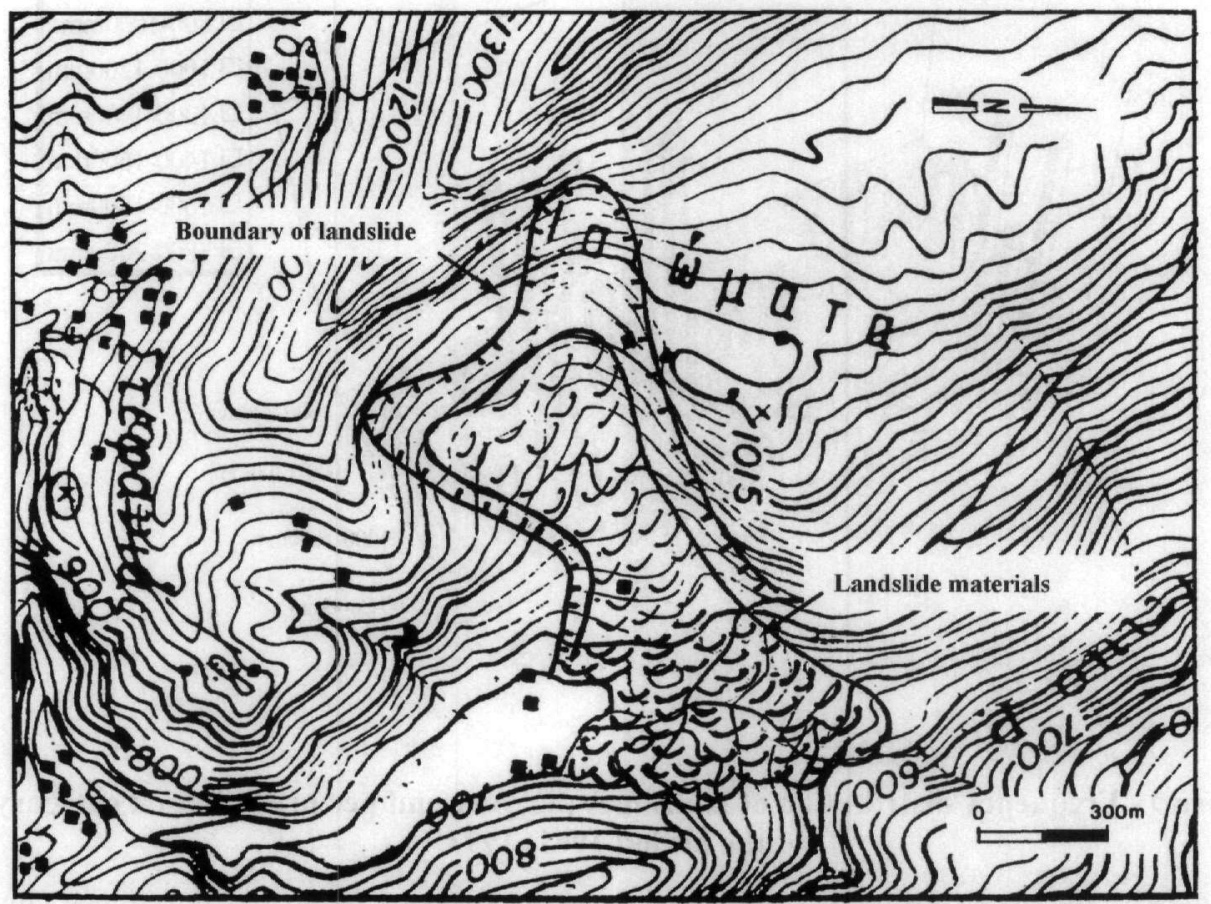

Figure 11 - Topographic map with the limits and the development of landslide in the Stefaniada area 
The volume of landslide materials that blocked the Koumpourgianitikos stream was more than $10 \times 10^{6} \mathrm{~m}^{3}$. By the movement of these materials an enormous natural dyke was shaped, with 80 $100 \mathrm{~m}$ length along the slope and about $150 \mathrm{~m}$ width. The operation of this dyke as a barrier is due to the composition of the geological formations and the way of their deposition in the Koumpourgianitikos stream (Liakouris 1995). The greater volume of these materials derived from the first flysch and occupied the lower level of the stream, while above these big fragments of limestones were deposited (Fig. 12).

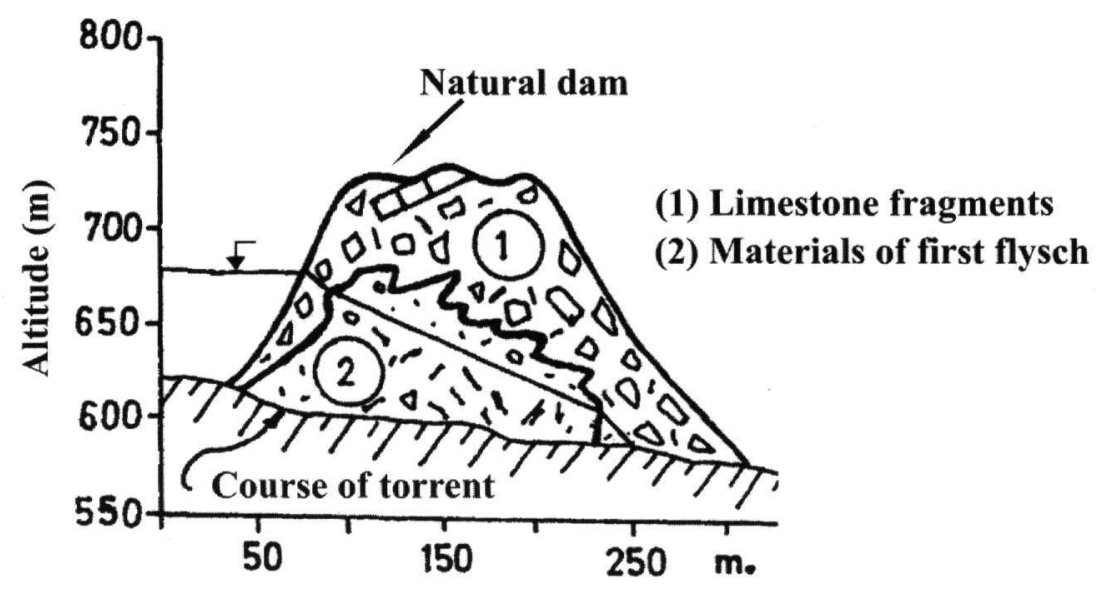

Figure 12 - Schematic section of natural "dam" through the Koumpourgianitikos stream (Liakouris, 1995)

\section{Conclusions}

Karditsa county is characterized by a complex geological structure, intense relief and heavy rainfall. These parameters in combination with man's intervention facilitate the occurrence of frequent and sometimes- extensive landslide movements, which cause serious damages in technical works (transportation network and other engineering works) and seriously affect urban development. In order to study the influence of all the above parameters and particularly that of rainfall to the occurrence of landslides, an investigation concerning data from 425 cases was carried out. So, a systematic inventory was implemented and a database was developed.

Also, for the statistical analysis of precipitation, the data obtained from 21 meteorological stations, covering a period of more than 32 years (1961- 1993), have been evaluated and analyzed. To this direction, by recounting the distribution of the meteorological stations in the county and the mean annual amount of the rainfall for each one, the rainfall map on a scale of 1:100,000 has been compiled.

The distribution of the mean annual rainfall amount for the mountainous region of the county for the period 1961- 1993 is increased during the years 1962-1963, 1966, 1979-1980, 1982, 1985 and 1987. This amount for most of the stations $(66 \%)$ is distributed in the categories of $1000-1200$ $\mathrm{mm}$ and 1200- $1400 \mathrm{~mm}$. Also, the great number of landslides occurs during the years 1963, 1979, 1982, 1985 and 1987.

Through the above data it is clearly observed that the mean annual amount of rainfall is closely related with the frequent occurrence of landslides in the mountainous region of Karditsa County. 
Further study relevant to these phenomena should be stressed towards their hazard zonation, by developing a model, which will evaluate the relative weight and interrelation of the parameters involved in the landslide problem. Thus, with the presupposition that the landslide occurrence depends mainly from extreme climatic events or changes and human intervention, it imposes their immediate approach in order to determine at the best their hazard grade. This will help the authorities for the safe planning of technical works and urban development.

\section{References}

Keefer, D.K., and others, 1987. Real- time landslide warning during heavy rainfall, Science, 238, 921-925.

Koukis, G., and Ziourkas, K., 1991. Slope instability phenomena in Greece: A statistical analysis, Bulletin of IAEG, 43, 47-60.

Koukis, G., Rozos, D., and Hadzinakos, I., 1996. Rainfall induced landslides in Achaia county, Greece, Proc. $7^{\text {th }}$ Int. Symp. on Landslides, Trondheim, 17-21 June 1996, 1929- 1934, Balkema Publ., Rotterdam.

Liakouris, D., 1995. The geology and the dams of National Electrical Company of Greece, National Electrical Company of Greece, Department of Education, Typo fos LTD, Athens, 349pp.

Lumb, P., 1975. Slope failures in Hong Kong, Q. J. Eng. Geol., vol. 8.

Nikolaou, N., Koukis, G., and Lambrakis, N., 1997. Rainfall and landslide manifestation correlation in Korinthos county, Greece, Int. Symp. on Eng. Geol. and Environment, 919- 924pp., Trondheim, Balkema Publ. Rotterdam.

Pyrgiotis, L., 1997. Engineering geological conditions in Karditsa county. Landslide phenomena in flysch formations, Ph.D. Thesis, University of Patras, Greece, 318pp.

Radbruck-Hall, D.H., and Crawther, K.C., 1973. Map showing areas of estimated relative amounts of landslides in California, U.S. Geol. Surv. Misc. Inv. Map, 1-747.

Terzaghi, K., 1950. Mechanism of landslides, Geol. Soc. of Am., Berkey Volume, 83-123.

Varnes, J.D., 1978. Slope movement types and processes. In Landslides: Analysis and Control (Schuster and Krizec, eds.), National Academy of Sciences, Special Report, 176, 11-33, Washington, D.C.

Varnes, J.D., 1984. Landslide hazard zonation; a review of principles and practice, UNESCO, Paris, 63pp. 